\title{
Retrospective Review of Anesthetic and Analgesic Regimens Used in Animal Research Proposals
}

\author{
Kathrin Herrmann 1,2 and Paul Flecknell 3 \\ ${ }^{1}$ Freie Universität Berlin, Department of Veterinary Medicine, Institute of Pharmacology and Toxicology, Berlin, Germany; ${ }^{2}$ current address: Johns \\ Hopkins University, Bloomberg School of Public Health, Baltimore, MD, USA; ${ }^{3}$ University of Newcastle, The Medical School, Comparative Biology \\ Centre, Newcastle upon Tyne, UK
}

\begin{abstract}
Pain has a profound effect on an animal's wellbeing. In Germany, researchers using animals have been legally required to reduce any possible pain, suffering, distress or lasting harm to an absolute minimum since 1972. To evaluate how these provisions have been implemented in practice, an assessment of refinements to experimental techniques was conducted by retrospectively reviewing 684 surgical interventions described in 506 animal research applications that were sent to the German competent authorities for approval in 2010. This paper focuses on the efficacy of proposed anesthesia and peri- and postoperative analgesia. Postoperative analgesia was not proposed for $30 \%$ of surgeries. Following $10 \%$ of procedures, animals were to be given pain relieving medication if the investigators decided this was necessary; however, structured assessments to detect pain were absent. Consequences of unalleviated pain and omission of pain assessment techniques are discussed, and some recommendations to improve anesthesia and analgesia are given. The findings of this review highlight the need for improvement, both to fulfil legal requirements and to improve animal welfare. To monitor compliance with animal welfare regulations and ensure good veterinary and scientific practices, education and training need to be intensified. Adherence to the items listed in the PREPARE and ARRIVE guidelines and the Gold Standard Publication Checklist (GSPC) should become legally binding.
\end{abstract}

\section{Introduction}

Refinement, the last R of the Three Rs principles (replacement, reduction, refinement), was first described by Russell and Burch 60 years ago (Russell and Burch, 1959), and pertains to " $[\mathrm{m}]$ ethods that minimize any pain, suffering, distress or lasting harm that may be experienced by the animals, and improve animal welfare. Refinement applies to all aspects of animal use, from the housing and husbandry to the scientific procedures performed upon them" (Graham and Prescott, 2015). The revised Directive, 2010/63/EU, requires European Union (EU) Member States to fully implement the Three Rs principles in their national laws (EU, 2010). Most states amended their national legislation in 2013. Well before that, following the revision of the German Animal Welfare Act in 1972, research workers using animals in Germany were required to reduce any possible pain suffering, distress, or lasting harm caused to animals to an absolute minimum (Germany, 1972). Nevertheless, due to limitations in the transparency of the authorization processes and reporting of animal research, it has been difficult to assess the extent to which experimental procedures were refined in practice.

Structured literature reviews of research that involved the use of laboratory animals have provided some insights. Animal research involving surgical procedures carried out on pigs, sheep, dogs, and non-human primates (Coulter et al., 2009), rabbits (Coulter et al., 2011) and rodents (Coulter et al., 2009; Richardson and Flecknell, 2005), published in peer-reviewed journals, has been analyzed with regard to analgesic and anesthetic administration. Stokes and colleagues (2009) focused on studies conducted during two time periods (2000-2001 and 2005-2006) to assess changes in the administration of analgesics and anesthetics to laboratory mice and rats undergoing surgical procedures. The study showed a trend towards improvement such as safer anesthetic regimens used in the later period examined, but this and an earlier review assessing analgesic use in rodents (Richardson and Flecknell, 2005) found that there was still significant scope for refinement, especially with respect to perioperative care. Richardson and Flecknell (2005) not only screened
Received April 1, 2018; Accepted September 13, 2018;

Epub September 14, 2018; ( The Authors, 2018.

ALTEX 36(1), 65-80. doi:10.14573/altex.1804011
This is an Open Access article distributed under the terms of the Creative Commons Attribution 4.0 International license (http://creativecommons.org/licenses/by/4.0/), which permits unrestricted use, distribution and reproduction in any medium, provided the original work is appropriately cited.

Correspondence: Kathrin Herrmann, Johns Hopkins University, Bloomberg School of Public Health, Center for Alternatives to Animal Testing (CAAT)

Baltimore, MD 21205, USA

(kherrma1@jhu.edu) 
the publications for postoperative analgesia but also e-mailed the authors or the respective Animal Ethics Committees a survey to find out when analgesia was administered independent of whether it was reported. The response rate was low (28 out of 101 papers) and only $18 \%$ of correspondents had given analgesics but not reported it. A systematic review of anesthesia, analgesia, and euthanasia methods used in anesthesiology, respiratory, and critical care research published in the ten highest ranked journals showed insufficient reporting of treatment regimens in experimental studies using small laboratory mammals; for example, the administration of analgesics was only reported in $19 \%$ of all painful interventions (Uhlig et al., 2015).

An assessment of papers published before 2011 and from 2014 to 2015 further confirmed that reporting of experimental refinement methods is still poor (Carbone and Austin, 2016). Whilst guidance documents specially written for reporting of animal studies, e.g., the Gold Standard Publication Checklist (GSPC) (Hooijmans et al., 2010) and the ARRIVE guidelines (Kilkenny et al., 2010), have been available since 2010, scientific publications still cannot be relied upon to present a detailed description of analgesia and anesthesia protocols. Most recently, an assessment of anesthetic and analgesic regimens in publications on studies involving non-human primates once again confirmed the lack of reporting of critical detail (Bertrand et al., 2018). Although many journals have adopted guidelines such as "ARRIVE", publications continue to omit key details of study design and conduct (e.g., Leung et al., 2018). This may be due to a lack of appreciation by researchers of the need to include these data in their publications. It therefore remains unclear to what extent the experimenters did not report their refinement practices although, for example, proper pain management may have been provided.

Besides the lack of information regarding refinement in the available publications, there is a general lack of transparency within animal research, as in all European Union Member States access to animal research proposals is generally restricted to members of the regulatory authorities. Thus, the degree to which refinement methods are applied in practice and the awareness of refinement options by research workers remains uncertain.

German animal research proposals must include detailed descriptions on how all procedures and interventions are to be conducted, including precise descriptions of surgeries and the application of refinements. The most humane and refined methods have to be used while still ensuring valid data collection; this is facilitated by a robust and effective harm-benefit analysis. For example, if less humane anesthetics are to be used or analgesia is withheld, this must be scientifically justified, and the hoped-for benefits of the research must outweigh also the additional harm.

To evaluate the use of experimental refinements in German laboratories, we retrospectively reviewed original animal research applications submitted to the German regulatory authorities for approval in 2010. The efficacy of the proposed anesthetic and peri- and postoperative analgesic regimens, the health monitoring, use of humane endpoints, killing methods, and the researchers' categorization of the severity of planned procedures were investigated. The goal was to assess the application of refinements before Directive 2010/63/EU came into effect and to make recommendations about where further improvements could be made. To our knowledge, this is the first assessment of its kind. In this paper, we focus on proposed anesthetic and periand postoperative analgesic regimens and discuss deficiencies and necessary improvements.

\section{Materials and methods}

In Germany, reviewing and licensing animal research proposals falls under the authority of each of the federal states. The 16 federal states have their own "competent authorities" for this task, generally comprised of state veterinarians. After negotiations with the highest authorities of the federal states, 14 of the 16 agreed to provide us access to original proposals for basic and applied research that had been granted a license. For the scope of our study, we selected all applications submitted to the participating competent authorities in 2010 that included recovery surgical procedures in mice and rats to assess appropriateness of anesthesia, perioperative analgesia, and postoperative care. Mice and rats are the two most commonly used species in Germany; over 2,000,000 mice and around 400,000 rats per year are used for scientific purposes in Germany (BMEL, 2014, 2017). Elsewhere in Europe, these rodents are also among the most frequently used species (EC, 2013; Home Office, 2017). A total of 506 applications met these criteria and were included in the analysis. These included 684 recovery surgical procedures (422 in mice and 262 in rats). The study was conducted anonymously (i.e., the individual research groups were not identified in the analysis).

Research proposals were included in this study if they met the following criteria:

1. Animal research proposal submitted to a German competent authority in 2010

2. Basic or applied research study

3. Species: mouse or rat

4. Procedure: surgical, recovery

5. Original proposal that was granted a project license

Research proposals were excluded from this study if they met the following criteria:

1. Application for the generation of genetically altered mice

2. Government-required animal testing, e.g., toxicity testing of drugs, vaccines, pesticides

3. Species other than mouse and rat

4. Procedure that did not involve recovery surgery

5. Proposal pre-assessed or rejected by members of the competent authority

We analyzed the experimental protocols described in the original applications. However, before approval of a final license, it is possible, and in some cases very likely, that the competent authorities requested changes to the proposed protocols. To follow up on the results of the competent authorities' assessments and on the amendments made in the process was not feasible. Also, the scope of our study was to evaluate the researchers' awareness of and expertise in the application of refinement methods, not that of the competent authorities. 

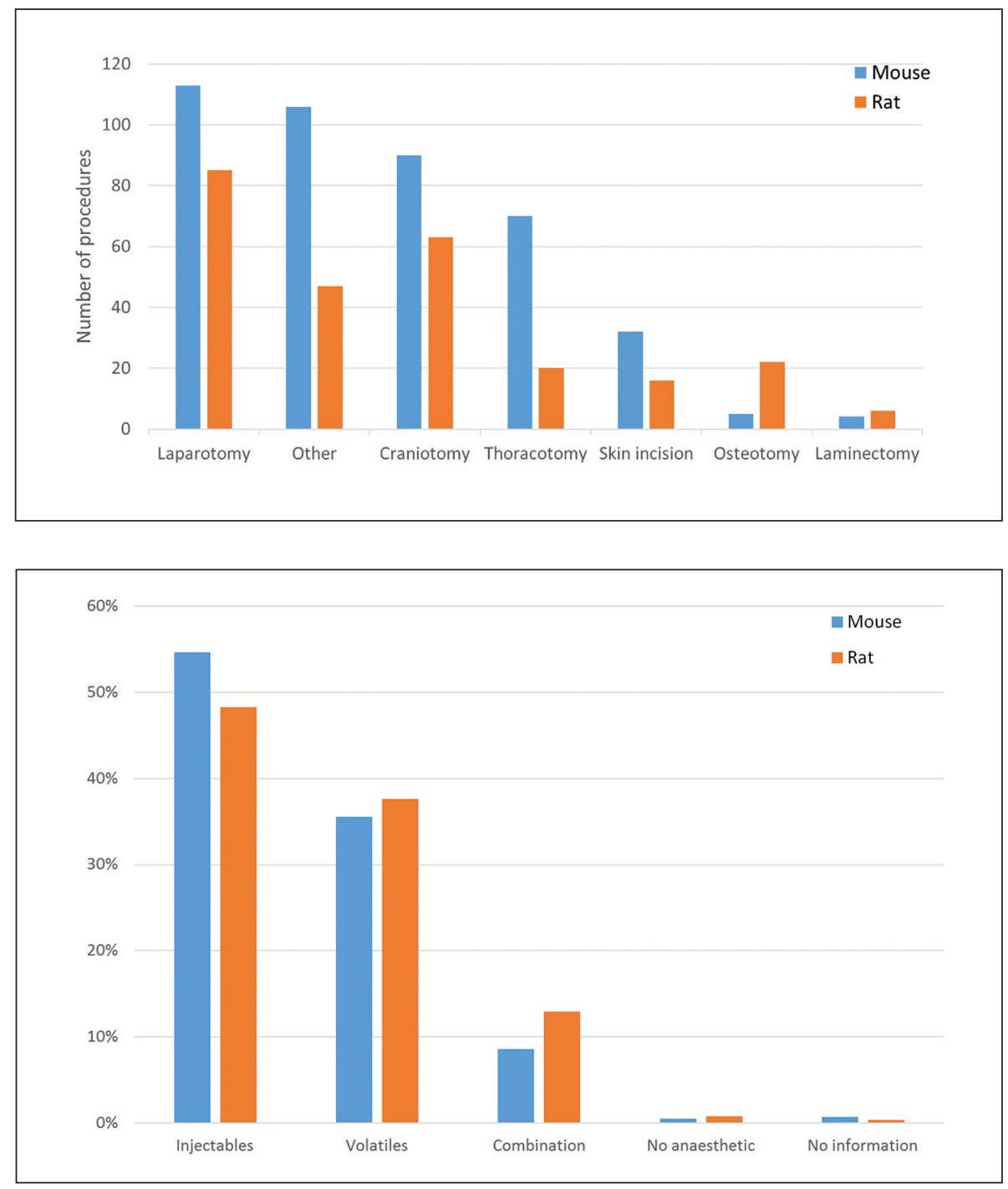

Fig. 1: Types and numbers of surgical procedures performed on mice and rats

A total of 684 surgical procedures were performed, 422 on mice and 262 on rats. "Other" refers to a general category of all surgeries that did not involve the opening of a body cavity, e.g., compression or ligation of nerves, or surgery to cause a middle cerebral artery occlusion.

Fig. 2: Anesthetic regimens used A total of 684 anesthetic regimens were performed, 422 on mice and 262 on rats.

\section{Results}

Some applications lacked required information. For example, in a few cases the type, the dose, or the route of administration of an anesthetic agent was missing; the justification as to why analgesia was withheld was mostly absent and there was generally no discussion on why certain anesthetic regimes were selected, even when they did not meet the standards of good veterinary practice. Project licenses were generally granted for up to three years, with the option to extend up to five years.

\subsection{Types of surgical interventions and frequency of endotracheal intubations}

The 506 assessed applications comprised 684 surgical procedures. Some animals underwent more than one surgery or in some cases several experimental groups underwent different surgical procedures. Out of the 684 surgical procedures, 422 were performed on mice and 262 on rats.
The most frequently performed surgical procedures on mice and rats were laparotomies. For rats, these were followed by craniotomies. For mice, the second most common procedure was surgery that did not involve the opening of a body cavity (Fig. 1); examples include neuropathic pain models such as compression or ligation of nerves (e.g., ischiatic nerve), implantation of catheters in veins and arteries (e.g., femoral artery or vein, jugular vein), a hindlimb ischemia model (ligation of the femoral artery), and a focal cerebral ischemia model (middle cerebral artery occlusion).

Endotracheal intubation was planned for $15 \%$ of surgeries in mice, the vast majority of these (82\%) for thoracotomies, and for $8 \%$ of surgeries on rats, over half of these being for thoracotomies.

\subsection{Anesthetic regimens and agents used}

Injectable anesthetics were the most commonly used anesthetics in procedures on both mice $(55 \%)$ and rats $(48 \%)$, followed by inhalant agents (mice, 36\%; rats, 38\%) (Fig. 2). A combination 


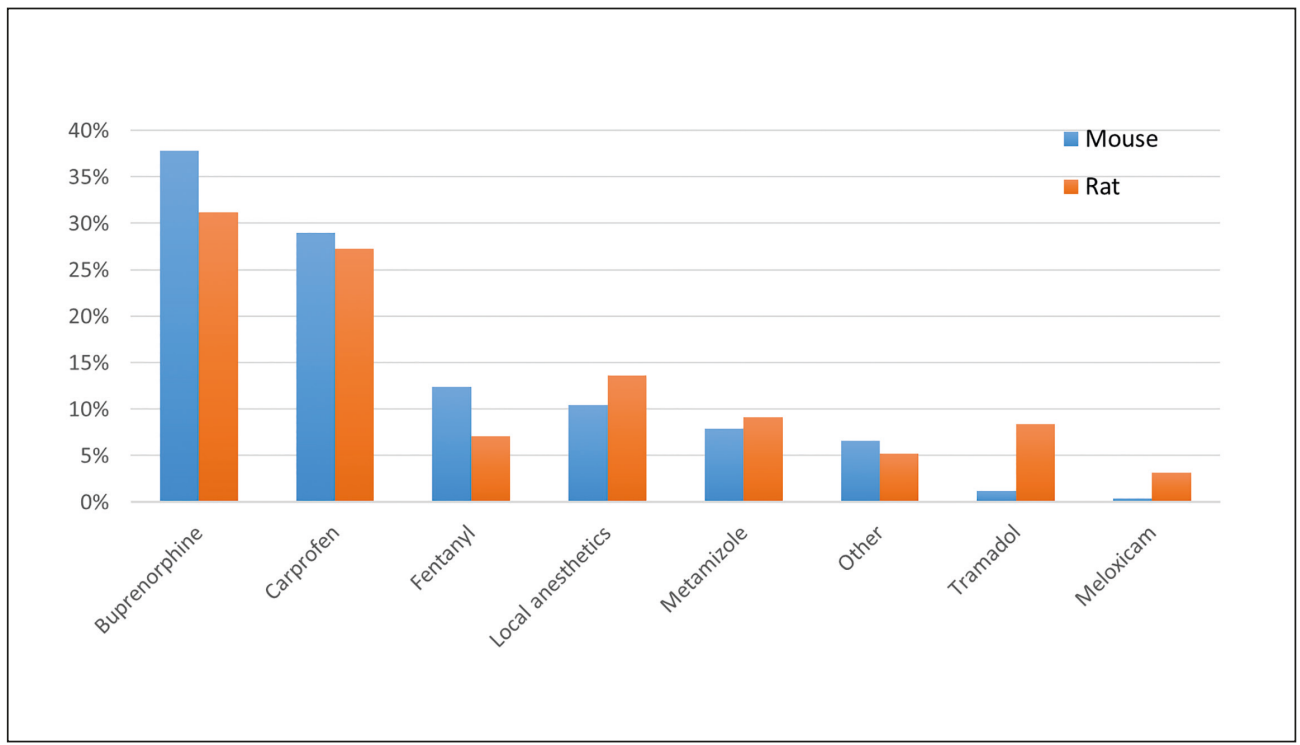

Fig. 3: Percentage of analgesia agents and local anesthetics given perioperatively to mice and rats Lidocaine, xylocaine, ropivacaine, bupivacaine, and amethocaine were used as local anesthetics. "Other" agents used included paracetamol (acetaminophen), flunixin meglumine, and butorphanol. of injectable and inhalational agents was used in about $10 \%$ of surgeries (Fig. 2). The authors did not provide information on anesthesia in $1 \%$ of surgeries. For another $1 \%$ of the surgical interventions it was not planned to use an anesthetic agent. Instead, the investigators intended to use hypothermia (cooling the animals to $1-4^{\circ} \mathrm{C}$ by laying them on ice for about six minutes) to immobilize neonatal mice and rats while carrying out intracranial injections of virions or neuroblasts.

\section{Injectable agents used for anesthesia}

Ketamine and xylazine were the most frequently used injectables in mice $(79 \%)$ and in rats $(70 \%)$. A completely reversible anesthetic regimen, a mixture of fentanyl, medetomidine, and midazolam, was used in $11 \%$ of mice and in $5 \%$ of rats. Choral hydrate was frequently used in rats $(6 \%)$ but was rarely administered to mice ( $<1 \%$ of procedures). Ketamine and medetomidine were also frequently used in rats $(6 \%)$ rather than in mice (2\%). Pentobarbital use ranked between $3 \%$ in mice and $5 \%$ in rats. Other single agents used in mice were medetomidine $(1 \%)$ and ketamine $(<1 \%)$. Acepromazine was combined with xylazine and ketamine for rats (5\%). In mice, acepromazine was combined with ketamine but this was used rarely $(<1 \%)$. The mixture of fentanyl, fluanisone, and midazolam was also used rarely for mouse and rat surgeries $(2 \%)$. In a few cases it was stated that reversible anesthetic agents would be antagonized at the end of the procedure.

\section{Inhalational agents}

Isoflurane was by far the most widely used inhalation agent ( $74 \%$ and $70 \%$ of procedures performed in mice and rats, respectively), followed by the combination of isoflurane and nitrous oxide in both species (15\%). For surgeries on mice, nitrous oxide was also used in combination with halothane (9\%) as well as halothane alone $(1 \%)$, whereas for rat surgical interventions no halothane use was reported, but sevoflurane (8\%) and methoxyflurane $(7 \%)$ were used.

\section{Combination of inhalational and injectable agents producing anesthesia}

The combination of inhalational agents with injectable anesthetics or sedatives was used in $9 \%$ of surgeries on mice and $13 \%$ of surgeries on rats. Here the most frequently administered injectable agents - ketamine and xylazine - were combined with isoflurane: $39 \%$ for mice; $56 \%$ for rats. The next most commonly used combination of anesthetics for mice was isoflurane and ketamine/midazolam and for rats isoflurane/nitrous oxide with ketamine/xylazine. In the majority $(61 \%)$ of cases anesthetic induction was performed with the injectable anesthetic/sedative, followed by the use of inhalational agents. In some cases, ether ( $3 \%$ of cases) or carbon dioxide ( $6 \%$ of cases) was used to initiate anesthesia in rats. Carbon dioxide was however frequently used to kill animals (Herrmann and Flecknell, 2018a).

\subsection{Perioperative analgesia}

The most frequently used perioperative analgesic agent for both mice and rats was buprenorphine (mice: $38 \%$; rats: $31 \%$ ), followed by carprofen (mice: $29 \%$; rats $27 \%$ ), and fentanyl (mice: 12\%; rats: 7\%) (Fig. 3). Local anesthetics such as lidocaine, xylocaine, ropivacaine, bupivacaine, and amethocaine were used in $10-13 \%$ of procedures. For instance, $22 \%$ of the craniotomies and $10 \%$ of the thoracotomies involved the application of local anesthetics at the surgical site. Metamizole was used in $8-9 \%$ of cases, followed by other analgesics such as paracetamol, flunixin meglumine, and butorphanol. Tramadol was used rarely in mice, but was administered after $8 \%$ of surgeries on rats. Meloxicam was a seldom administered agent in both species (Fig. 3).

When inhalational anesthetics with no or minimal analgesic properties were used, it was assessed whether and when they were combined with analgesics. In the case of isoflurane, $25 \%$ of mice and $28 \%$ of rats received no pain relief, and $13 \%$ of mice and $18 \%$ of rats received pain relief at the end of surgery, while the others received pain relief pre- or intraoperatively (Fig. 4). 


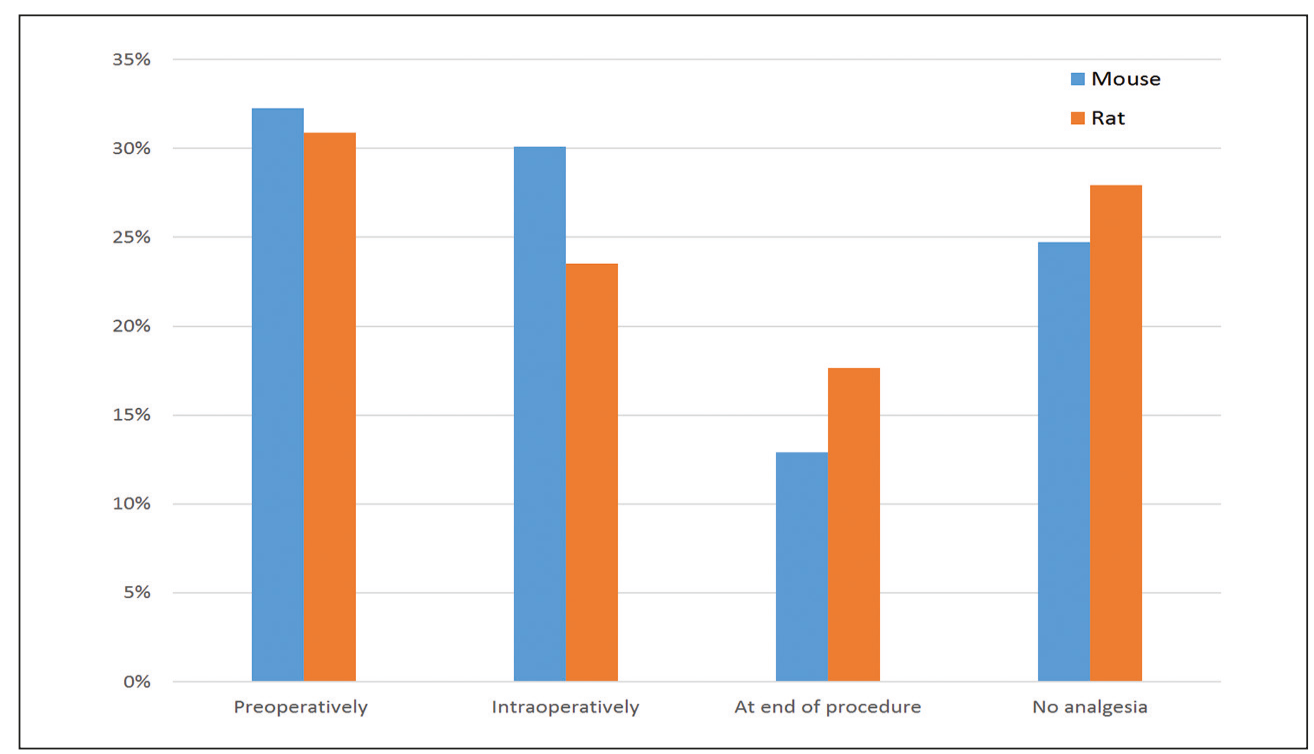

Fig. 4: Time of analgesic administration when isoflurane was used Of all inhalational anesthetic regimens, isoflurane was used in $74 \%$ and $70 \%$ of surgical interventions in mice and rats, respectively.

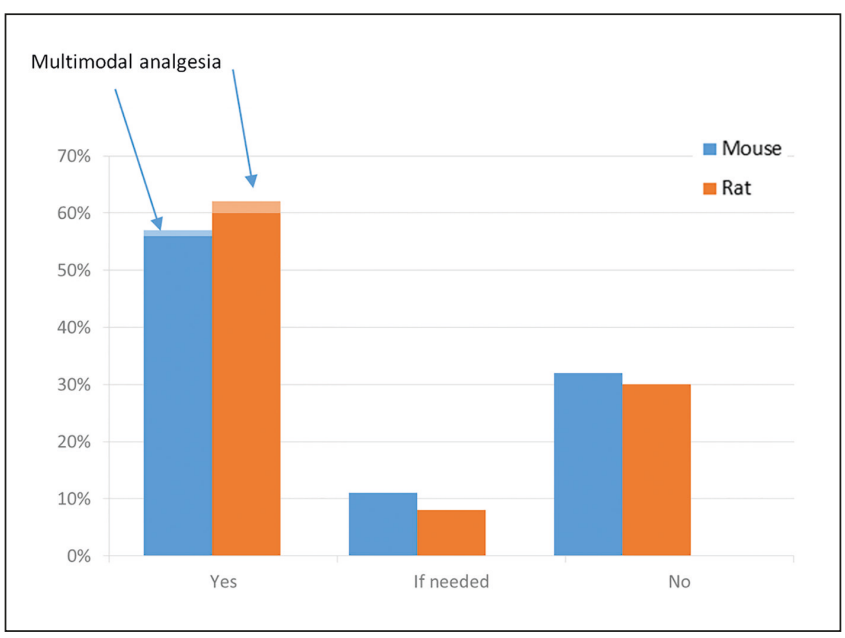

Fig. 5: Decision on administration of analgesic treatment following surgical interventions

(422 on mice and 262 on rats): yes, no, and "if needed" according to the judgement of the researcher.

For injectable agents with no specific analgesic activity such as pentobarbital or chloral hydrate we reviewed whether these were combined with analgesics: With pentobarbital, analgesia was not provided in $55 \%$ of surgical procedures on mice and in $75 \%$ of surgical procedures on rats. Chloral hydrate, an injectable anesthetic that was most frequently used for craniotomies in rats, was most often combined with tramadol given intraoperatively and, less often, with a local anesthetic.

\subsection{Postoperative analgesia}

Postoperative analgesia was administered following 57\% of the surgical interventions on mice, less than $1 \%$ being multimodal, and $62 \%$ of procedures on rats. In only $1 \%$ and less than $2 \%$ of cases, respectively, were these multimodal analgesic regimens (Fig. 5).
The surgical procedures for which multimodal analgesia was provided postoperatively are listed in Table 1 (for mice) and 2 (for rats). In one of the two mouse procedures, the multimodal approach was optional, depending on pain being detected. The first three postsurgical regimens in Table 2 are identical and were used after various surgical procedures all described in the same research application. One of the aortic banding surgeries, a commonly used experimental model for pressure overload-induced cardiac hypertrophy and heart failure, used the multimodal approach only in case the animals did not drink enough, because metamizole was supplied via the drinking water, and/or the animals showed signs of pain. The applications involving aortic banding (Tab. 2) represent two of very few that mentioned they would monitor water intake. One application also stated the amount that the rats were expected to drink from 8 weeks old ( $8-12 \mathrm{ml} / \mathrm{kg}$ body weight).

No postoperative analgesia was intended following $32 \%$ of surgeries on mice and $30 \%$ of surgeries on rats (Fig. 5). Reasons for withholding analgesia were given for $24 \%$ of these surgeries on mice and $33 \%$ of these surgeries on rats. The most frequent explanations were that it was not considered necessary as pain was anticipated to be minor, and that the analgesic agent could influence study outcomes. In $11 \%$ of surgical procedures on mice and in $8 \%$ of surgical procedures on rats the investigators declared that they would administer analgesia only "if needed" (Fig. 5). Pain management would be considered "when signs of pain and/ or suffering were observed" or "in case of signs of moderate pain". Some stated that, according to their experience, analgesia was not necessary for the planned surgical interventions and that the surgery was "tolerated well by the animals". Overall, these applications contained no description of how a structured pain assessment would be conducted. The general health score sheets $15 \%$ of surgical procedures had included focused on various health indicators, including humane endpoints, most of which are not specific for pain (Herrmann and Flecknell, 2018a,b).

Similar to intraoperative pain management for mice and rats, buprenorphine (mice: 33\%; rats: 34\%) and carprofen (both: 33\%) 


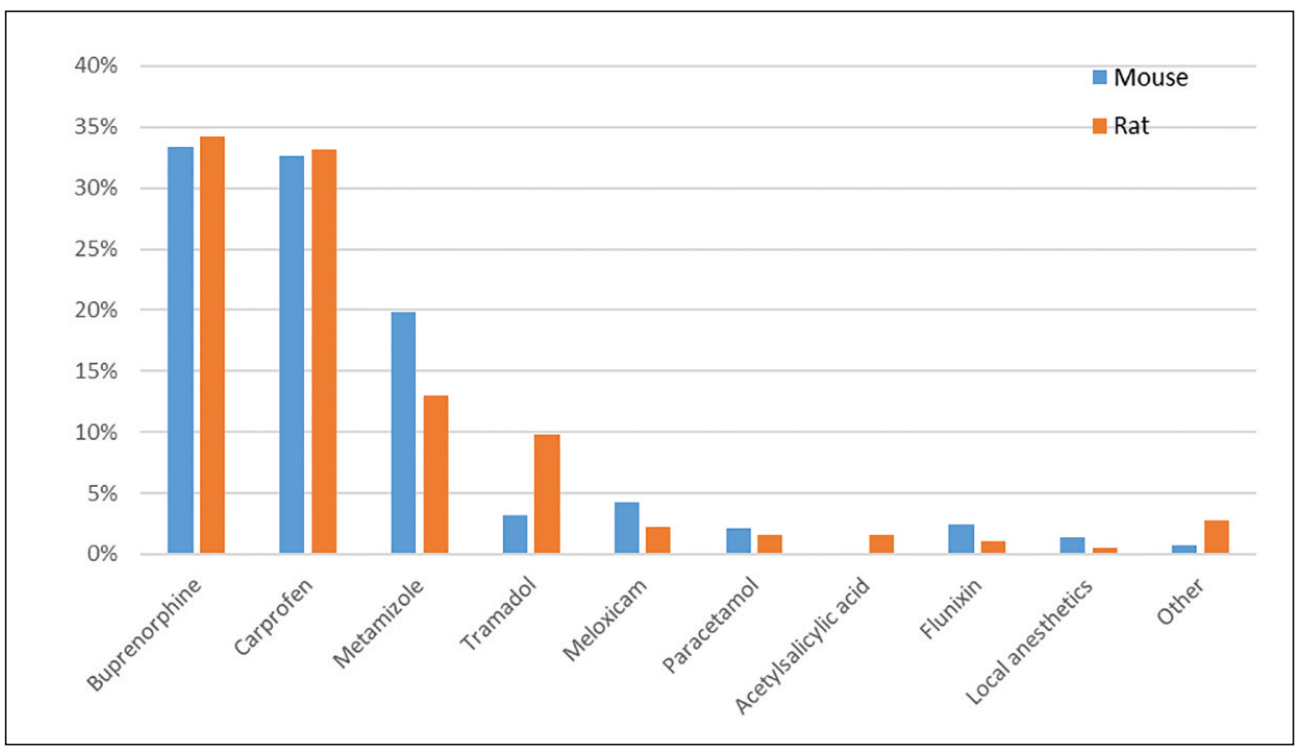

Fig. 6: Postoperative analgesic agents used No analgesia was provided after $32 \%$ of mouse surgeries and after $30 \%$ of rat surgeries. Proposed local anesthetics were lidocaine, xylocaine and bupivacaine. Other analgesics included piritramide, fentanyl, ketamine and ketoprofen. were most commonly utilized to manage postoperative pain, followed by metamizole (mice: 20\%; rats: 13\%) (Fig. 6). Tramadol was used postoperatively in $10 \%$ of surgeries in rats and in $3 \%$ of surgeries in mice. Meloxicam was more popular after interventions in mice $(4 \%)$ than in rats $(2 \%)$. Other rarely used agents were paracetamol, acetylsalicylic acid, flunixin meglumine, and local anesthetics (Fig. 6).

Information regarding duration and frequency of postoperative analgesic application was incomplete. When indicated, buprenorphine was often given subcutaneously (s.c.) between once and three times a day for one to three days and longer, but some administered buprenorphine intraperitoneally (i.p.) or intramuscularly (i.m.). Carprofen was given mostly s.c., but at times i.p., i.m., orally, or via the drinking water. When not given via the drinking water, it was administered once or twice daily for one to three days, or occasionally longer. Metamizole, paracetamol, tramadol, and acetylsalicylic acid were usually given via the drinking water. Duration of administration of metamizole varied between one to five days, in some cases up to seven days and longer. Paracetamol was given mostly for two to three days. For tramadol, the duration was rarely mentioned and for acetylsalicylic acid not at all. The route of administration of local anesthetics was mostly not specified.

Analgesic doses given were usually within the standard published ranges with the occasional low, e.g., $2.5 \mathrm{mg} / \mathrm{kg}$ carprofen in rats, or high, e.g., $30 \mathrm{mg} / \mathrm{kg}$ of carprofen in mice. Meloxicam was dosed mostly at $0.2 \mathrm{mg} / \mathrm{kg}$. Dosages for metamizole supplied via the drinking water ranged between $1.3 \mathrm{mg} / \mathrm{ml}$ and $2.5 \mathrm{mg} / \mathrm{ml}$. Other doses noted were $110 \mathrm{mg} / \mathrm{kg}, 200 \mathrm{mg} / \mathrm{kg}$, and $300 \mathrm{mg} / \mathrm{kg}$. Paracetamol was provided at $1-3 \mathrm{mg} / \mathrm{ml}$ drinking water. Tramadol drinking water doses were 30 to $50 \mathrm{mg} / \mathrm{kg} / 8 \mathrm{~h}$ or $25 \mathrm{mg} / \mathrm{l}$ up to 200 $\mathrm{mg} / \mathrm{l}$ drinking water. It was rarely reported whether the drinking water intake would be measured, and how much an animal, based on body weight, was expected to drink to assure sufficient drug levels. A few investigators stated that they would administer the analgesic s.c. if animals showed pain despite having the agent in their drinking water. In one proposal, administration of tramadol via the drinking water was started preoperatively. A small number of investigators stated that they would switch to another analgesic agent or give an additional analgesic if pain was not controlled effectively. Some asserted that they would provide analgesia until no more pain was observed. However, information in regard to performing a structured pain assessment was absent.

\subsection{Health and pain monitoring}

Health score sheets were available for 108 out of 684 surgical procedures $(15 \%)$; their quality varied. The vast majority monitored general indicators of deteriorating health not specific to pain - such as weight loss, alterations in body temperature, and tumor size. When declaring that the animal's behavior and overall health condition would be monitored, it was mostly unclear to what extent this would be done and what would be done to alleviate clinical signs (analgesia, special bedding or other measures of intensive care). The planned frequency of monitoring of the animals was mentioned for $33 \%$ of all surgical interventions, and in the majority of cases these checks were to be done once a day. More results on health monitoring, severity of procedures, and assessment outcomes with regard to humane study endpoints and killing methods are published elsewhere (Herrmann and Flecknell, 2018a,b).

\section{Discussion}

We found shortcomings in all areas we assessed. First and foremost, pain was often not alleviated or was unlikely to be alleviated effectively. Following $30 \%$ of surgical interventions, no analgesia was planned, and in another $10 \%$ of procedures it would be alleviated only if pain was observed but monitoring generally seemed to be infrequent or lacking. Reasons for withholding analgesia, if included, may indicate not only a general lack of monitoring, a lack of pain assessment, and a lack of pain recognition skills; they also imply that concerns about the neg- 
Tab. 1: Post-procedural multimodal analgesic approaches following surgery on mice

Postoperative analgesia was administered following $57 \%$ of the surgical interventions on mice, less than $1 \%$ being multimodal.

\begin{tabular}{|c|c|c|}
\hline Type of surgical intervention & Intraoperative regimen & Multimodal regimen \\
\hline $\begin{array}{l}\text { Sternotomy; cryoinjury-induced } \\
\text { myocardial infarction }\end{array}$ & $\begin{array}{l}\text { Induction: isoflurane } 1.5-3 \mathrm{Vol} \% \\
\text { maintenance: isoflurane } 0.8-1 \mathrm{Vol} \% \\
\text { nitrous oxide } 60 \% \text {; O2 } 40 \% \text {; intubation; } \\
\text { intercostal space infiltration with ropivacaine; } \\
\text { buprenorphine, } 0.1 \mathrm{mg} / \mathrm{kg} \text { i.p.; carprofen, } \\
5 \mathrm{mg} / \mathrm{kg} \text { s.c. }\end{array}$ & $\begin{array}{l}\text { Buprenorphine, } 0.1 \mathrm{mg} / \mathrm{kg} \text { i.p., } 3 \mathrm{x} / \mathrm{d} \text {, } \\
\text { duration: } 5 \mathrm{~d} \text {; carprofen, } 5 \mathrm{mg} / \mathrm{kg} \text { s.c., } \\
\text { 1x/d, duration: } 10 \mathrm{~d}\end{array}$ \\
\hline $\begin{array}{l}\text { Craniotomy; chronic cranial window } \\
\text { preparation (bone flap removal and } \\
\text { replacement by glass cover) }\end{array}$ & $\begin{array}{l}\text { Ketamine, } 130 \mathrm{mg} / \mathrm{kg} \text { and xylazine, } \\
10 \mathrm{mg} / \mathrm{kg} \text { i.p.; carprofen, } 5 \mathrm{mg} / \mathrm{kg} \text { s.c., } \\
\text { buprenorphine, } 0.05 \mathrm{mg} / \mathrm{kg} \text { i.p. }\end{array}$ & $\begin{array}{l}\text { Carprofen, } 5 \mathrm{mg} / \mathrm{kg} \text { s.c.; duration: } 3 \mathrm{~d} \text {; } \\
\text { if pain detected: buprenorphine, } \\
0.05 \mathrm{mg} / \mathrm{kg} \text { i.p. }\end{array}$ \\
\hline
\end{tabular}

Tab. 2: Post-procedural multimodal analgesic approaches following surgical interventions on rats

Postoperative analgesia was administered following $62 \%$ of procedures on rats, $2 \%$ being multimodal.

\begin{tabular}{|c|c|c|}
\hline Type of surgical intervention & Intraoperative regimen & Multimodal regimen \\
\hline $\begin{array}{l}\text { Laparotomy; clamping of Ligamentum } \\
\text { hepatoduodenale (Pringle maneuver); } \\
\text { ischemia for } 30 \text { minutes }\end{array}$ & $\begin{array}{l}\text { Buprenorphine, } 0.05-0.1 \mathrm{mg} / \mathrm{kg} \text { s.c.; } \\
\text { isoflurane: induction, } 4-5 \mathrm{Vol} \% \text {; } \\
\text { maintenance, } 1.5-3 \mathrm{Vol} \%\end{array}$ & $\begin{array}{l}\text { Carprofen, } 5-10 \mathrm{mg} / \mathrm{kg} \text { s.c. } 1 \mathrm{x} / \mathrm{d} \text {; } \\
\text { buprenorphine }{ }^{*} \text { s.c. } 2 \mathrm{x} / \mathrm{d} \text {, duration: } 3 \mathrm{~d}\end{array}$ \\
\hline $\begin{array}{l}\text { Laparotomy; 2/3-hepatoectomy } \\
\text { (in some groups combined with } \\
30 \text { minute-Pringle maneuver) }\end{array}$ & $\begin{array}{l}\text { Buprenorphine, } 0.05-0.1 \mathrm{mg} / \mathrm{kg} \text { s.c.; } \\
\text { isoflurane: induction, } 4-5 \mathrm{Vol} \% ; \\
\text { maintenance, } 1.5-3 \mathrm{Vol} \%\end{array}$ & $\begin{array}{l}\text { Carprofen, } 5-10 \mathrm{mg} / \mathrm{kg} \text { s.c. } 1 \mathrm{x} / \mathrm{d} \text {; } \\
\text { buprenorphine }{ }^{*} \text { s.c. } 2 \mathrm{x} / \mathrm{d} \text {, duration: } 3 \mathrm{~d}\end{array}$ \\
\hline $\begin{array}{l}\text { Laparotomy; placing of gastrointestinal } \\
\text { tube }\end{array}$ & $\begin{array}{l}\text { Ketamine, } 40-50 \mathrm{mg} / \mathrm{kg} \text { and xylazine, } \\
1-2 \mathrm{mg} / \mathrm{kg} \text { i.p. }\end{array}$ & $\begin{array}{l}\text { Carprofen, } 5-10 \mathrm{mg} / \mathrm{kg} \text { s.c. } 1 \mathrm{x} / \mathrm{d} \text {; } \\
\text { buprenorphine }{ }^{*} \text { s.c. } 2 \mathrm{x} / \mathrm{d} \text {, duration: } 3 \mathrm{~d}\end{array}$ \\
\hline Partial sternotomy; aortic banding & $\begin{array}{l}\text { Ketamine, } 80-100 \mathrm{mg} / \mathrm{kg} \text { and xylazine, } \\
1.5-5 \mathrm{mg} / \mathrm{kg} \text { i.p.; injection of carprofen* } \\
\text { at the beginning (route not further specified); } \\
\text { intubation; injection of metamizole at end } \\
\text { of procedure (route not further specified) }\end{array}$ & $\begin{array}{l}\text { Metamizole* via drinking water for } 3 \mathrm{~d} \text {; } \\
\text { carprofen* s.c. } 1 \mathrm{~d} \text { (longer if needed) }\end{array}$ \\
\hline Partial sternotomy; aortic banding & $\begin{array}{l}\text { Ketamine, } 80-100 \mathrm{mg} / \mathrm{kg} \text { and xylazine, } \\
1.5-5 \mathrm{mg} / \mathrm{kg} \text { i.p.; intubation; metamizole* } \\
\text { s.c. at end of procedure }\end{array}$ & $\begin{array}{l}\text { Metamizole, } 0.05 \mathrm{~g} \text { in } 50 \mathrm{ml} \text { drinking } \\
\text { water mixed with } 0.25 \mathrm{ml} 20 \% \text { glucose } \\
\text { solution for } 3 \mathrm{~d} \text {; if needed additionally } \\
\text { carprofen* s.c. } 1 \mathrm{x} / \mathrm{d}\end{array}$ \\
\hline $\begin{array}{l}\text { Placement of titanium implant on two } \\
\text { critical size defects ( } 5 \mathrm{~mm} \text { diameter) } \\
\text { per scull }\end{array}$ & Ketamine, $90 \mathrm{mg} / \mathrm{kg}$ and xylazine, $10 \mathrm{mg} / \mathrm{kg}$ i.p. & $\begin{array}{l}\text { Carprofen, } 5 \mathrm{mg} / \mathrm{kg} 2 x / \mathrm{d} \text {; buprenorphine, } \\
0.05-0.1 \mathrm{mg} / \mathrm{kg} 2 \mathrm{x} / \mathrm{d} \text {, both s.c.; duration: } \\
1 \mathrm{~d} \text {, max. } 2 \mathrm{~d}\end{array}$ \\
\hline
\end{tabular}

*no dose given

ative effects of analgesics on study outcomes were greater than the concerns about untreated pain.

Considering the severity of planned surgical interventions, it was unexpected that use of multimodal analgesia was almost non-existent. Furthermore, preventive analgesia was often not provided as, for example, anesthetics that have no analgesic properties (e.g., isoflurane) were to be used; this was the case in a quarter of these procedures, and in another $13-18 \%$, analgesia was planned to be given too late, and thus, the animals would recover consciousness without pain relief. Moreover, the use of local anesthetics for severe surgeries such as thoracotomies was very low ( $10 \%$ of thoracotomies).

In the following, we discuss the problems we identified in detail and provide some information as to how these could be improved or resolved. We are confident that implementation of these re- finements would both significantly improve animal welfare and improve the quality of data obtained.

\subsection{Unalleviated pain}

As we found that pain management during and after surgery was often absent or inadequate, we commence the discussion with general considerations on the effects of unalleviated pain. Researchers often appear to be concerned that (side)effects produced by analgesics (and anesthetics) could potentially influence or even confound study outcomes and data (as also seen in our study sample). However, there is an abundance of information on the pharmacodynamics, pharmacokinetics, unwanted effects, toxicity, and interactions of analgesics and anesthetics with other drugs (e.g., Flecknell, 2016; Gaynor and Muir, 2014; Grimm et al., 2015; Muir and Hubbell, 2014; Informationssystem CliniPharm CliniTox ${ }^{1}$ ) to

\footnotetext{
1 CliniPharm Wirkstoffdaten. http://www.vetpharm.uzh.ch/perldocs/index i.htm
} 
guide investigators when designing their studies. In addition, there is an increasing number of recommendations for the refinement of certain models and procedures, for example, for models of ischemic stroke (Percie du Sert et al., 2017), for rheumatoid arthritis (Hawkins et al., 2015), for sepsis and septic shock (Lilley et al., 2015), for experimental autoimmune encephalomyelitis (EAE) (Wolfensohn et al., 2013a), and for procedures involving seizures, convulsions, and epilepsy (Lidster et al., 2016; Wolfensohn et al., 2013b). These guidelines were composed by experts based on their knowledge of the particular models and the value of potential refinements. Furthermore, specialists in veterinary anesthesia and analgesia in a research setting can give additional, project-specific advice and guidance.

Unalleviated pain has profound effects on the animal, leading to emotional, behavioral, and physiological changes (see Jirkof, 2017; Peterson et al., 2017). The immune system is suppressed due to pain stimulating glucocorticoid and catecholamine release. Responses to pain vary between individuals, and consequently are hard to predict, which potentially makes pain a poorly controlled study variable. In comparison, the influence of anesthetic and analgesic agents on the data is more foreseeable than the effects of unalleviated pain, distress, and suffering on in vivo research. In addition, use of perioperative analgesics - if based on the need of the individual animal elicited by properly and frequently conducted structured pain assessments - will most likely have relatively minor effects on the animal model. Confounding effects are more likely to be introduced by analgesics when the agents are given over an extended time period or in unnecessarily high dosages. The likely effects are often overestimated and based on studies in which analgesics were administered at elevated doses and for time periods longer than needed in most experimental settings (e.g., Hall et al., 1996). Furthermore, models designed to be of relevance to clinical conditions in humans should be treated as in the human setting, where pain would generally be alleviated whenever possible. A plan for adequate and controlled pain management should be developed as part of the study protocol. To sufficiently manage pain, the choice of anesthetics and analgesics, their dose, administration route, frequency and duration of treatment, and a pain assessment plan should be tailored to the individual research project, treatment group and, if necessary, to an individual animal's needs.

\subsection{Need for refinement of anesthetic protocols} Endotracheal intubation

Intubation was performed in $8 \%$ and $15 \%$ of surgeries (rats and mice, respectively), and the majority of these were thoracotomies. When opening the thoracic cavity, endotracheal intubation is generally indicated as the animals require mechanical ventilation to maintain respiratory function. In addition, there are certain disease models where intubation and mechanical ventilation is of considerable benefit. For example, the lesion size in experimental models of stroke is influenced by cerebral blood flow and the degree of cerebral vasodilation. These variables are markedly affected by changes in arterial carbon dioxide, which can be maintained at a consistent level by mechanical ventilation (Liu et al., 2009). Tracheal intubation might appear challenging in small rodents but it is relatively easy to perform with the correct apparatus (Flecknell, 2016).

\section{Hypothermia}

For experiments where neonatal mice and rats were to be injected intracranially, the researchers planned to use hypothermia to immobilize them. The investigators would then inject the animals' brains with virions or neuroblasts. In neonatal rodents, the nociceptive pathways are thought to be not yet fully developed (Fitzgerald, 2005). However, recovery from hypothermia is possibly associated with pain as it has been shown to lead to c-Fos activation (Rhodes, 2009). Since there are anesthetic agents available for neonatal mice and rats such as methoxyflurane (Danneman and Mandrell, 1997) or fentanyl/fluanisone (Clowry and Flecknell, 2000), the use of hypothermia should be abandoned. It is our understanding that the German competent authorities generally do not allow this controversial practice (Projektgruppe der Genehmigungsbehörden, personal communications, 2016).

\section{Pentobarbital}

A number of surgical interventions were conducted under the hypnotic agent pentobarbital, given intraperitoneally. Doses ranged from $36 \mathrm{mg} / \mathrm{kg}$ body weight up to $60 \mathrm{mg} / \mathrm{kg}$ in mice and up to $70 \mathrm{mg} / \mathrm{kg}$ in rats whereas recommended doses are between 40 $50 \mathrm{mg} / \mathrm{kg}$ (Field et al., 1993). Pentobarbital has a narrow safety margin and is best used to provide a light plane of anesthesia rather than for surgical interventions, for which doses close to the lethal dose may be required (Flecknell, 2016). The high $\mathrm{pH}$ of pentobarbital (11) causes pain when injected intraperitoneally. Pentobarbital also results in prolonged sleep time in rats (120-240 min) and mice (120-180 min) (Flecknell, 2016), and during this period, animals have depressed cardiovascular and respiratory systems and are susceptible to hypothermia.

\section{Chloral hydrate}

Choral hydrate was rarely used in mice, but was the second most frequently used agent in rats. However, it can cause adynamic ileus in rats (Fleischman et al., 1977) and it often produces only a light plane of anesthesia. Most investigators using choral hydrate planned to give perioperative analgesia. Nonetheless, due to the danger of causing adynamic ileus, chloral hydrate should be replaced by more effective and safer agents (Baxter et al., 2009).

\section{Use of ketamine or medetomidine as the sole agent}

There were few cases for which the use of ketamine or medetomidine as single agents was planned. Used alone, these agents cause sedation and mild to moderate analgesia, but they must be combined with other agents to produce surgical anesthesia. The combination of ketamine with acepromazine or with midazolam does not usually provide an anesthetic depth necessary for surgery in either species (Flecknell, 2016); hence, for surgical interventions, additional agents are needed.

\section{Use of inappropriate inhalational agents for induction of anesthesia}

For rats, ether was used in 3\% and carbon dioxide in $6 \%$ of protocols to initiate anesthesia. Induction with both of these agents 
is distressing and aversive due to irritation of the mucus membranes. Coughing, salivation, and at times laryngospasm occur from inhaling ether (Flecknell, 2016). Carbon dioxide is strongly aversive, and causes distress and fear in rodents (e.g., Chisholm et al., 2013; Kirkden et al., 2008; Leach et al., 2002a,b, 2004; Makowska and Weary, 2009; Marquardt, 2013; Niel and Weary, 2007; Niel et al., 2008; Wong et al., 2013; Ziemann et al., 2009) and thus, its use as a killing agent has been controversial for many years. Rats and mice are unwilling to tolerate exposure to $\mathrm{CO}_{2}$ long enough to lose consciousness (Leach et al., 2002b, 2004; Niel and Weary, 2007; Niel et al., 2008). Food incentives to stay in the gas chamber (Leach et al., 2004; Niel and Weary, 2007) and withholding food for up to 24 hours to increase their motivation to stay in the chamber longer as well as varying the gas flow rates did not change the time they were willing to tolerate carbon dioxide (Niel et al., 2008). When comparing carbon dioxide to other anesthetic gases, it was found to be the most aversive gas for both mice and rats, with the least aversive being enflurane and halothane for mice and halothane for rats (Leach et al., 2002a). Other studies compared rats' aversion to carbon dioxide with isoflurane or halothane exposure and concluded that the fluorinated hydrocarbons were less aversive than carbon dioxide (Kirkden et al., 2008; Makowska and Weary, 2009; Wong et al., 2013; Young, 2006).

\section{Recommendations}

\section{Dosing and route of administration}

Drug doses vary between species, strains, and individuals and depend on age, sex, and health condition of the individual animal (Flecknell, 2016). Therefore, we only discuss chosen dosages if they were outside of the standard range. Injectable anesthetics were the most widely used agents in both mice and rats. They can provide safe and effective anesthesia, but this is most easily achieved when given intravenously, so that the dosage can be adjusted to provide the desired effect in that particular animal. However, this is generally not feasible for small rodents, who thus receive most injectable anesthetic agents intraperitoneally (i.p.) and less often subcutaneously (s.c.) or intramuscularly (i.m.). Several studies have shown that intraperitoneal applications have a high failure rate (6-20\% for experienced personnel) with some of the material being injected, e.g., into the fatty tissues, viscera, or caecum (Ballard, 2009; Coria-Avila et al., 2007; Gaines Das and North, 2007; Lewis et al., 1966). Intramuscular injections can be painful, and in the case of ketamine, for example, they can produce necrosis (Smiler et al., 1990). The subcutaneous route seems the least invasive, however, data comparing the accuracy of dosing with i.p. administration is not available. Since injectable anesthetics are administered as a single dose, overdosing or underdosing can easily occur. To avoid complications, agents with a wide safety margin should be used as well as agents whose effects can be reversed using specific antagonists.

\section{Reversible anesthetic agents}

Due to their small body size, rodents are prone to hypothermia, and respiratory and cardiovascular depression (Fleischmann et al., 2016), and mortality increases with prolonged postsurgical sleep time. This risk can be reduced by using anesthetic agents that can be reversed such as medetomidine and xylazine with atipamezole; midazolam with flumazenil and fentanyl with butorphanol, buprenorphine or naloxone. Some researchers who used reversible anesthetic regimens planned to antagonize these at the end of the procedure. This should be done routinely to avoid long sleep times and ensure a faster recovery.

Most investigators in our study sample used ketamine and xylazine, a regimen associated with prolonged recovery periods (Albrecht et al., 2014). Ketamine/xylazine and ketamine/medetomidine could be partially antagonized with atipamezole; this should be considered to reduce recovery time.

\section{Pre-medication and balanced anesthesia}

Isoflurane was the most frequent inhalational anesthetic used. There seems to be a general trend towards using inhalant anesthetics, probably because induction is rapid, anesthesia levels can be adjusted to the individual animal's needs, and recovery from anesthesia is fast. Isoflurane undergoes almost no biotransformation; however, it is mildly pungent (Eger, 1981). Most commonly used inhalational agents are to some degree pungent to rodents, and studies have shown increased aversion and distress after repeated exposure to, e.g., isoflurane and halothane (Makowska and Weary, 2009). Hence, it is advisable to use pre-medication such as fentan$\mathrm{yl} /$ fluanisone or midazolam/fentanyl for induction before maintenance with an inhalational agent. Other commonly used pre-medication agents are medetomidine, dexmedetomidine, or xylazine.

Another advantage of using sedatives and analgesics as pre-anesthetic medication is that this produces a balanced anesthesia where the dosage of each component can be reduced, while inducing general anesthesia of sufficient depth with fewer side effects. For example, administration with midazolam and fentanyl has been shown to improve sevoflurane anesthesia for moderately painful surgeries in mice (Lipiski et al., 2017). Depressant effects of sevoflurane on the respiratory rate and the negative post-anesthetic effects on heart rate were decreased by use of pre-anesthetic medication.

Hence, to avoid unnecessary animal distress as well as to minimize potential negative effects of anesthesia on the research subject, balanced anesthesia should be the norm.

\subsection{Inadequate analgesia}

\section{Lack of preventive analgesia}

When anesthetics with no or minimal analgesic properties were used, e.g., in the case of isoflurane, $25 \%$ of mice and $28 \%$ of rats received no pain relief, and $13 \%$ of mice and $18 \%$ of rats received pain relief only at the end of surgery. Anesthetic agents without analgesic properties such as isoflurane and sevoflurane should always be combined with analgesics to ensure sufficient pain relief at the time the animal regains consciousness (Flecknell, 2016; Miller and Richardson, 2011). Since most analgesics only reach full onset of action 15 to 45 minutes after administration, it is advisable to administer the analgesic preoperatively. Preventive analgesia reduces both noxious stimuli reaching the central nervous system during surgery and peripheral inflammation (Miller and Richardson, 2011). Perioperative analgesics may also have an anesthetic sparing effect (Penderis and Franklin, 2005). 
Lack of use of local anesthetics

Splash blocks (instillation of local anesthetics at surgery site) were used in $22 \%$ of craniotomies; for $10 \%$ of mice and rat thoracotomies local anesthetics were used for intercostal infiltration or as splash blocks. Incorporating local anesthetics into intraoperative regimens of surgeries known to cause severe pain is a valuable refinement. Combining lidocaine $(10 \mathrm{mg} / \mathrm{kg})$ and bupivacaine $(5 \mathrm{mg} / \mathrm{kg})$ provides safe and effective analgesia in a range of species (Flecknell, 2018).

\section{Absence of multimodal analgesia}

Multimodal analgesia, the use of different classes of analgesics, including local anesthetics, opioids, and nonsteroidal anti-inflammatory drugs (NSAIDs) in combination, represents current best practice. Besides this approach being the most effective in managing pain, it also helps to avoid side effects caused by the use of high doses of a single analgesic agent (Miller and Richardson, 2011; Flecknell, 2016). However, in the reviewed studies, multimodal analgesia was rarely chosen.

\section{Intake via the drinking water}

The sole application of an analgesic agent in the drinking water was a frequent method of analgesic administration, but effectiveness of this approach for managing pain is highly questionable as it is uncertain if the individual animal consumes sufficient analgesic to reach effective plasma concentrations (Sauer et al., 2016). This is especially difficult to achieve during the light phase of the animal's photoperiod when mice and rats drink infrequently (Graf et al., 2016). An additional problem can be the unfamiliar taste of the medicated drinking water. To accustom the animals to the water mix, provision should start a day or two before the surgical intervention (as planned in one of the reviewed proposals). A recent study demonstrated that the mixture of tramadol and paracetamol was voluntarily consumed via the drinking water in sufficient amounts to alleviate mild to moderate postsurgical pain (Jirkof et al., 2018). It was concluded that this protocol should at least partially alleviate pain, but the authors considered that additional analgesic agents would be required after surgical interventions that caused more severe pain. Analgesic delivery via the drinking water should be combined with another analgesic, given by injection, to provide analgesia during the light phase of the animal's photoperiod when water intake is decreased (Sauer et al., 2016). It is also practicable to train animals to consume analgesics in a palatable base, and to dose animals individually in this way (Kalliokoski et al., 2011; Leach at al., 2010).

Studies on the efficacy of the oral application of metamizole, an agent that seems especially popular in German laboratories (see Fig. 3 and 6), appear lacking. Metamizole is a pyrazolone derivate with antipyretic and analgesic properties. Its use in medical practice has been prohibited in many countries since the 1970 s after its use was linked to agranulocytosis. However, it appears that the risk of metamizole-induced agranulocytosis was exaggerated (Jasiecka et al., 2014) and the agent continues to be available in Germany. A study to verify if it is an effective postoperative analgesic in rodents is urgently needed.

\section{Analgesic dosing}

Analgesic doses should be selected according to the anticipated and then actual severity of the surgical intervention, the strain and the animal's individual response to the treatment (Wright-Williams et al., 2013). The general dose recommendations for carprofen given to mice are 4-5 mg/kg (e.g., GV-SOLAS and TVT, 2015) and for ketoprofen $2-5 \mathrm{mg} / \mathrm{kg}$ (Matsumiya et al., 2012). Depending on the degree of acute pain, a 2- to 4-fold higher dose can be needed for the analgesic to be efficient (Matsumiya et al., 2012). However, these increased doses of NSAIDs may result in undesirable side effects such as gastrointestinal ulceration.

Meloxicam, at the doses proposed, is unlikely to be effective in managing postoperative pain since significantly higher doses are required (Roughan et al., 2016; Wright-Williams et al., 2007). A recent re-assessment of the efficacy of meloxicam for postlaparotomy pain in mice suggested that it had anti-inflammatory activity but failed to prevent pain, even at high doses (Roughan et al., 2016). A slow-release formulation of meloxicam also did not control pain of rats after skin incision under general anesthesia (Seymour et al., 2016).

\section{Slow release formulations}

Repeated handling and restraint causes distress (Balcombe et al., 2004; Meijer et al., 2006) and can add to postsurgical pain in newly operated animals (Jirkof et al., 2015). Thus, the frequency of analgesic injections should be minimized. However, the serum concentrations for, e.g., buprenorphine (Temgesic $\left.{ }^{\circledR}\right)$ indicate that its duration of action in mice is less than 8 hours (Jirkof et al., 2015). Thus, to maintain effective serum concentrations, this agent should be given at approximately 6-hour intervals. Slow-release formulations could be administered to reduce this to once every 24-48 hours in mice (Jirkof et al., 2015; Kendall, 2016) and up to once every 72 hours in rats (Foley et al., 2011; Chum, 2014). However, these slow-release formulations are currently only available in the USA.

\section{Non-provision of analgesia: reasons, responsibilities, and refinement}

Approximately $30 \%$ of surgeries on mice and rats were not to be followed with any postoperative analgesia. However, pain occurrence is to be expected for all surgical procedures. Annex VIII of Directive 2010/63/EU (similar to previous guidance documents on severity of procedures) classifies "surgery under general anaesthesia and appropriate analgesia, associated with post-surgical pain, suffering or impairment of general condition" as moderate in severity and "surgical and other interventions in animals under general anaesthesia which are expected to result in severe or persistent moderate postoperative pain, suffering or distress or severe and persistent impairment of the general condition of the animals" as severe (EU, 2010). In contrast, almost $40 \%$ of the 684 surgeries included in our review were classified as mild by the researchers (Herrmann and Flecknell, 2018b). Explanations for not expecting and not detecting pain might be the overall low frequency of observation of the animals, the absence of structured pain assessments, as well as a general lack of knowledge about pain-related behaviors in mice and rats and the impact/severity of surgical interventions performed on them. 
Ensuring that the animals used in procedures experience the minimum of pain, distress, and suffering is one of the investigator's primary responsibilities (Germany, 1986). Research applications for surgical procedures not planning to provide postoperative pain management with no scientifically plausible explanation should not be approved. If withholding pain relief is indeed necessary from a scientific standpoint, the harm-benefit analysis has to demonstrate that the anticipated benefit of the research outweighs and thus justifies the painful experience for the animal. When analyzing the restrictions of research studies in detail, a solution/compromise can often be found. It might not be possible to provide the animal with the best available pain management, but it is almost always possible to improve the animal's welfare, at least by avoiding factors that can cause and increase pain and distress. Appropriate intra- and postoperative measures also help the animals to recover more rapidly.

Postsurgical pain is likely to be present for at least 48 hours after surgery, and for longer when more invasive procedures such as thoracotomies or orthopedic procedures are undertaken. Since all opioids that are currently available in the EU act for less than 8 hours, repeated administration will be required to provide effective analgesia. When used alone, particularly in mice, NSAIDs provide insufficient analgesia following major surgery. Although handling and restraint to administer additional analgesics can cause stress, prior positive reinforcement training of the animals and use of tunnel handling of mice can greatly reduce this adverse effect. In any event, the stress of handling is likely to be minimal in comparison to unalleviated post-surgical pain.

\subsection{Lack of recognition and assessment of pain}

For $10 \%$ of all surgical procedures, the researchers stated that analgesia would not be necessary, but would be provided if signs of pain or suffering were observed. As mentioned before, information concerning structured pain assessment was generally absent. Our findings correlate with results from a study conducted in the UK where almost none of the 28 institutions in the survey used pain assessment methods. Although their efficacy was not assessed, the British laboratories routinely provided the animals with analgesics (Hawkins, 2002).

In many cases, investigators stated that animals would be monitored "frequently" without defining what this would mean. When the frequency of health inspections was specified, most of these checks were to be done once a day. Yet, daily inspections are a minimum legal requirement for healthy animals (EC, 2007). Even before Directive 2010/63/EU was published, recovery surgical procedures were generally rated as at least moderate in severity (Martini et al., 2000). Thus, animals that have undergone surgery require much more frequent monitoring to assure that pain is recognized and managed effectively.

\section{Recommendations}

Positive reinforcement training

The degree to which pain is perceived and the way the presence of pain is expressed by animals varies greatly between species, strains, sexes, age, health status, as well as among individuals. Therefore, proper pain assessment schemes are necessary as it is insufficient to administer an analgesic and assume that pain is alleviated. Observations to assess pain are more likely to be successful when animals are familiar with the people who observe and handle them and provide veterinary care. This highlights the importance of frequent positive interactions with the animals. Besides gentle handling practices (Hurst and West, 2010; Gouveia and Hurst, 2013), successes of positive reinforcement training in mice (Leidinger, 2018) and rats (Schuppli et al., 2017) leading to positive animal-human relationships that could help with ensuring their pain is managed effectively.

\section{Monitoring criteria}

Common behavioral alterations in mice and rats that can indicate pain are, e.g., decreased activity levels (Wright-Williams et al., 2007; Karas, 2002), sleep disturbances, reduced water and food intake (Liles et al., 1993; Carstens and Moberg, 2000), changes in nest building (Deacon, 2012; Jirkof et al., 2013; Jirkof, 2014), burrowing (Deacon, 2006, 2009, 2012; Jirkof et al., 2010; Jirkof, 2014), and grooming behavior (Miller et al., 2016). Specific behaviors associated with abdominal pain in rodents include pressing the abdomen against the cage floor, raising the tail while walking, flinching, twitching of back muscles, partial loss of balance when walking, and lifting one leg straight out behind (Wright-Williams et al., 2007; Leach et al., 2012; Miller et al., 2012, 2016). The observation and scoring of these behaviors can be complemented with monitoring of burrowing and nest building behaviors as in some strains these have been shown to be useful not only for disease progression, but also as signs of pain and distress (Jirkof, 2014). A prerequisite is that baseline data is obtained for the particular strain.

Another approach to pain assessment is the use of the grimace scale for mice (Langford et al., 2010; Leach et al., 2012) and rats (Sotocinal et al., 2011). The Mouse Grimace Scale (MGS) and Rat Grimace Scale (RGS) have been used successfully to assess spontaneous, postoperative pain that can be detected for 36 to 48 hours after surgery (Matsumiya, 2012). For research purposes, the MGS and RGS are used by scoring images taken from digital video. This system also has been used by animal care staff and research workers (Matsumiya, 2012), who confirmed user friendliness and sensitivity of the method (e.g., Faller et al., 2015). Using multiple blinded observers, previously overlooked low-level pain was identified in a study where the system was used to assess the efficacy of postsurgical analgesia protocols following thoracotomy for surgical induction of myocardial infarction (Faller et al., 2015). Furthermore, this tool has shown potential in the search for effective analgesic dose ranges. The use of the MGS showed that currently recommended doses of carprofen and ketoprofen were insufficient to manage postsurgical pain, and that paracetamol was an inadequate agent at any dose (Matsumiya et al., 2012). The grimace scale should be combined with monitoring other pain-related behaviors mentioned above, water and food intake, locomotor and exploratory activity, as well as changes in nest building and burrowing behavior in order to optimize pain management strategies. Structured pain assessments take time and therefore require sufficient numbers of trained personnel. However, they are central to assuring the efficacy of analgesic treatment. 


\section{Monitoring in the nocturnal phase}

Rodents are generally more active in the dark phase of their photoperiod (Wells, 2017), so other useful tools to employ are remote video-monitoring of animals in their home cage and, in certain settings, the use of automated cages that are able to detect and record rapid changes in normal behavior (Miller et al., 2011; Wright-Williams et al., 2013; Jourdan et al., 2001). Limitations of currently available automated cages are that abnormal behaviors which are associated with pain such as pressing the abdomen on the cage floor or slow contortion of abdominal flank muscles are not detected.

\section{Conclusions}

The findings of this first-of-its kind review of original animal research proposals confirms international trends detected in various previous appraisals (see also Bara and Joffe, 2014; Taylor, 2010; Pound and Nicol, 2018; Uhlig et al., 2015). Although reporting of analgesia and anesthesia in scientific publications is often incomplete, it is highly probable that, for example, postoperative analgesia was not provided if it is not mentioned in the publication. Our assessment shows that legal requirements to comprehensively apply available methods of refinement were not followed in the study sample. In particular, provision of pain management was often either not planned or the proposed regimens were not appropriate, and optimal techniques such as multimodal analgesia were almost never used to alleviate postoperative pain in laboratory rodents. Pain assessment tools and schemes were not utilized, and effective health monitoring seemed to be lacking. To assess whether the situation has changed since Directive 2010/63/EU came into effect in 2013, it would be important for this study to be repeated, as well as expanded to other EU Member States.

Since animal research workers are legally bound to reduce discomfort, pain, and suffering of animals to an absolute minimum, a possible explanation for the deficiencies in the research applications is that they have not received sufficient education as well as adequate on-going training in refinement methods and animal welfare.

The number of investigators who underestimated the severity of their procedures (see Herrmann and Flecknell, 2018b) also suggests there is a knowledge gap. To ensure that animal research is conducted in the most responsible and least invasive way, resulting in findings that are valid and reproducible, professional assistance and comprehensive training are required. It is important to educate researchers not only on how experiments, husbandry, and care could be refined, but also why this is central to producing high quality research data. To adhere to all the Three Rs, specialists in reduction, replacement, and alternative, animal-free approaches should also be consulted during study planning. Every research institution should ensure that these experts are available to advise and assist research workers when planning, designing, conducting, and reporting their studies; and if a research institution does not have such expertise, outside specialists should be sought. Education and training is one of the focus areas of the new Directive, and a guidance document to improve and harmonize education and training in the EU was produced by an Expert Working Group (National Competent Authorities, 2014). Incorporating the learning outcomes into the relevant training modules and ensuring that all new research workers attend formal courses to deliver this training effectively should improve the implementation of refinements. Refresher training for more experienced researchers is recommended and more formal requirements for this should also be considered.

It is critical that clear descriptions regarding the provision of adequate pain management (and all other refinements) are included in research proposals and in publications to avoid needless pain and suffering of the animals. Full disclosure in the proposals and in the publications is also essential to enable the replication of the studies and to understand the findings. Researchers build their work on the work of other researchers, mostly by using information given in publications, and regulatory authorities and bodies, such as animal research and ethics committees, Animal Welfare Bodies (AWBs), and Animal Care and Use Committees (ACUCs), make their decisions on the content presented in proposals. Hence, openness about all aspects and details is imperative.

Finally, investigators should closely follow the PREPARE (Smith et al., 2017) and ARRIVE guidelines or the Gold Standard Publication Checklist (GSPC) to provide essential data required for interpretation of their results. Funding agencies and scientific journals still do not demand full disclosure of this information (Baker et al., 2014; Carbone and Austin, 2016; Enserink, 2017; Reichlin et al., 2016). A recent randomized controlled trial of an Intervention to Improve Compliance with the ARRIVE guidelines revealed that the request to fill in an ARRIVE checklist did not lead to full compliance with the guidelines in the manuscript (Hair et al., 2018). Thus, legal enforcement of compliance with preparation and reporting checklists, in addition to comprehensive training on all checklist items, appears critical to fulfil already existing legal requirements as well as responsibilities to the public, who ultimately funds research and, as opinion polls (e.g., Clemence and Leaman, 2016) show, expects that suffering is minimized.

\section{References}

Albrecht, M., Henke, J., Tacke, S. et al. (2014). Effects of isoflurane, ketamine-xylazine and a combination of medetomidine, midazolam and fentanyl on physiological variables continuously measured by telemetry in Wistar rats. BMC Vet Res 10, 198. doi:10.1186/s12917-014-0198-3

Baker, D., Lidster, K., Sottomayor, A. and Amor, S. (2014). Two years later: Journals are not yet enforcing the ARRIVE guidelines on reporting standards for pre-clinical animal studies. PLoS Biol 12, e1001756. doi:10.3410/f.718233317.793491394

Balcombe, J. P., Barnard, N. D. and Sandusky, C. (2004). Laboratory routines cause animal stress. Contemp Top Lab Anim Sci 43, 42-51. http://www.ingentaconnect.com/content/aalas/ jaalas/2004/00000043/00000006/art00009

Ballard, T. (2009). Intraperitoneal route of administration - How accurate is this technique. Animal Technology and Welfare 8, 17-18. 
Bara, M. and Joffe, A. R. (2014). The ethical dimension in published animal research in critical care: The public face of science. Crit Care 18, R15. doi:10.1186/cc13694

Baxter, G. M., Murphy, K. L., Taylor, P. M. and Wolfensohn, S. E. (2009). Chloral hydrate is not acceptable for anesthesia or euthanasia of small animals. Anesthesiology 111, 209. doi:10.1097/ ALN.0b013e3181a8617e

Bertrand, H. G. M. J., Sandersen, C. and Flecknell, P. A. (2018). Reported analgesic and anaesthetic administration to non-human primates undergoing experimental surgical procedure: 20102015. J Med Primatol 47, 217-225. doi:10.1111/jmp.12346

BMEL - Bundesministerium für Ernährung und Landwirtschaft (2014). Anzahl der für Versuche und andere wissenschaftliche Zwecke verwendeten Wirbeltiere. Stand 01.12.2014. http://www. bmel.de/SharedDocs/Downloads/Tier/Tierschutz/2013-Tierver suchszahlenGesamt.pdf? blob=publicationFile

BMEL (2017). Versuchstierdaten 2016. https://www.bmel.de/ SharedDocs/Downloads/Tier/Tierschutz/Versuchstierdaten2016. pdf?__blob=publicationFile

Carbone, L. and Austin, J. (2016). Pain and laboratory animals: Publication practices for better data reproducibility and better animal welfare. PLoS One 11, e0155001. doi:10.1371/journal. pone. 0155001

Carstens, E. and Moberg, G. P. (2000). Recognizing pain and distress in laboratory animals. ILAR J 41, 62-71. doi:10.1093/ ilar.41.2.62

Chisholm, J., De Rantere, D., Fernandez, N. J. et al. (2013). Carbon dioxide, butnotisoflurane, elicits ultrasonic vocalizations in female rats. Lab Anim 47, 324-327. doi:10.1177/0023677213493410

Chum, H. H., Jampachairsri, K., McKeon, G. P. et al. (2014). Antinociceptive effects of sustained-release buprenorphine in a model of incisional pain in rats (Rattus norvegicus). J Am Assoc Lab Anim Sci 53, 193-197. http://www.ingentaconnect.com/content/ aalas/jaalas/2014/00000053/00000002/art00011\#

Clemence, M. and Leaman, J. (2016). Public Attitudes to Animal Research in 2016. A report by Ipsos MORI for the Department for Business, Energy \& Industrial Strategy, Ipsos MORI Social Research Instititute. https://www.ipsos.com/sites/ default/files/publication/1970-01/sri-public-attitudes-to-animalresearch-2016.pdf

Clowry, G. J. and Flecknell, P. A. (2000). The successful use of fentanyl/fluanisone ('Hypnorm') as an anaesthetic for intracranial surgery in neonatal rats. Lab Anim 34, 260-264. doi: $10.1258 / 002367700780384771$

Coria-Avila, G. A., Gavrila, A. M., Menard, S. et al. (2007). Cecum location in rats and the implications for intraperitoneal injections. Lab Anim (NY) 36, 25-30. doi:10.1038/laban0707-25

Coulter, C., Flecknell, P. and Richardson, C. (2009). Reported analgesic administration to rabbits, pigs, sheep, dogs and nonhuman primates undergoing experimental surgical procedures. Lab Anim 43, 232-238. doi:10.1258/la.2008.008021

Coulter, C., Flecknell, P., Leach, M. and Richardson, C. (2011). Reported analgesic administration to rabbits undergoing experimental surgical procedures. BMC Vet Res 7, 12. doi:10.1186/17466148-7-12

Danneman, P. J. and Mandrell, T. D. (1997). Evaluation of five agents/ methods for anesthesia of neonatal rats. Lab Anim Sci 47, 386-395.
Deacon, R. (2006). Burrowing in rodents: A sensitive method for detecting behavioural dysfunction. Nat Protoc 1, 118-121. doi:10.1038/nprot.2006.19

Deacon, R. (2009). Burrowing: A sensitive essay, tested in five species of laboratory rodents. Behav Brain Res 200, 128-133. doi:10.1016/j.bbr.2009.01.007

Deacon, R. (2012). Assessing burrowing, nest construction, and hoarding in mice. J Vis Exp (59), e2607. doi:10.3791/2607

EC - European Commission (2007). 2007/526/EC Commission Recommendation of 18 June 2007 on guidelines for the accommodation and care of animals used for experimental and other scientific purposes (notified under document number C(2007) 2525). OJ L197, 1-89. http://eur-lex.europa.eu/legal-content/ EN/TXT/?uri=uriserv:OJ.L_.2007.197.01.0001.01.ENG

EC (2013). Report from the Commission to the Council and the European Parliament. Seventh Report on the Statistics on the Number of Animals used for Experimental and other Scientific Purposes in the Member States of the European Union. $\operatorname{COM}(2013) 859$ final. http://eur-lex.europa.eu/LexUriServ/ LexUriServ.do?uri=COM:2013:0859:FIN:EN:PDF

Eger, E. I. (1981). Isoflurane: A review. Anesthesiology 55, 559576. doi:10.1097/00000542-198111000-00014

Enserink, M. (2017). Sloppy reporting on animal studies proves hard to change. Science 357, 1337-1338. doi:10.1126/science. 357.6358 .1337

EU - European Union (2010). Directive 2010/63/EU of the European Parliament and of the Council of 22 September 2010 on the protection of animals used for scientific purposes. OJ L276, 33-79. http://eur-lex.europa.eu/legal-content/EN/TXT/ HTML/?uri=CELEX:32010L0063\& from=EN

Faller, K. M., McAndrew, D. J., Schneider, J. E. and Lygate, C. A. (2015). Refinement of analgesia following thoracotomy and experimental myocardial infarction using the mouse grimace scale. Exp Physiol 100, 164-172. doi:10.1113/expphysiol. 2014.083139

Field, K. J., White, W. J. and Lang, C. M. (1993). Anaesthetic effects of chloral hydrate, pentobarbitone and urethane in adult male rats. Lab Anim 27, 258-269. doi:10.1258/002367793780745471

Fitzgerald, M. (2005). The development of nociceptive circuits. Nat Rev Neurosci 6, 507-520. doi:10.1038/nrn1701

Flecknell, P. A. (2016). Laboratory Animal Anaesthesia. $4^{\text {th }}$ edition. Massachusetts, USA: Academic press.

Flecknell, P. A. (2018). Rodent analgesia: Assessment and therapeutics. Vet $J$ 232, 70-77. doi:10.1016/j.tvj1.2017.12.017

Fleischman, R. W., McCracken, D. and Forbes, W. (1977). Adynamic ileus in the rat induced by chloral hydrate. Lab Anim Sci 27, 238-243. http://europepmc.org/abstract/med/857088

Fleischmann, T., Jirkof, P., Henke, J. et al. (2016). Injection anaesthesia with fentanyl-midazolam-medetomidine in adult female mice: Importance of antagonization and perioperative care. $L a b$ Anim 50, 264-274. doi:10.1177/0023677216631458

Foley, P. L., Liang H. and Crichlow, A. R. (2011). Evaluation of a sustained- release formulation of buprenorphine for analgesia in rats. J Am Assoc Lab Anim Sci 50, 198-204. http://www.ingen taconnect.com/content/aalas/jaalas/2011/00000050/00000002/ art00007\#

Gaines Das, R. and North, D. (2007). Implications of experimental 
technique for analysis and interpretation of data from animal experiments: Outliers and increased variability resulting from failure of intraperitoneal injection procedures. Lab Anim 41, 312-320. doi:10.1258/002367707781282802

Gaynor, J. S. and Muir, W. W. (2014). Handbook of Veterinary Pain Management-E-Book. Missouri, USA: Elsevier Health Sciences.

Ersetzen mit:

Germany (1972). Animal Welfare Act as amended in 1972. Section 9.1, Sentence 3. https://bit.ly/2Rlhlmz

Germany (1986). Animal Welfare Act as amended in 1986. Section 9. https://bit.ly/2r8Ve7m

Gouveia, K. and Hurst, J. L. (2013). Reducing mouse anxiety during handling: Effect of experience with handling tunnels. PLoS One 8, e66401. doi:10.1371/journal.pone.0066401

Graf, R., Cinelli, P. and Arras, M. (2016). Morbidity scoring after abdominal surgery. Lab Anim 50, 453-458. doi:10. 1177/0023677216675188

Graham, M. L. and Prescott, M. J. (2015). The multifactorial role of the 3 Rs in shifting the harm-benefit analysis in animal models of disease. Eur J Pharmacol 759, 19-29. doi:10.1016/j. ejphar.2015.03.040

Grimm, K. A., Lamont, L. A., Tranquilli, W. J. et al. (eds.) (2015). Veterinary Anesthesia and Analgesia: The Fifth Edition of Lumb and Jones. Iowa, USA: John Wiley \& Sons, Inc. doi:10. 1002/9781119421375

GV-SOLAS and TVT (2015). Committee on Anaesthesia of GV-SOLAS Supported by The working group 4 of TVT (German veterinary association for animal welfare). Pain Management in Laboratory Animals. http://www.gv-solas.de/fileadmin/user upload/pdf_publikation/Anaest._Analgesie/Schmerztherapie_ Mai2015_e.pdf

Hair, K., Macleod, M. R., Sena, E. S. and IICARus Collaboration (2018). A randomised controlled trial of an intervention to improve compliance with the ARRIVE guidelines (IICARus). bioRxiv, 370874. doi:10.1101/370874

Hall, T. J., Jagher, B., Schaeublin, M. and Wiesenberg, I. (1996). The analgesic drug buprenorphine inhibits osteoclastic bone resorption in vitro, but is proinflammatory in rat adjuvant arthritis. Inflamm Res 45, 299-302. doi:10.1007/BF02280995

Hawkins, P. (2002). Recognizing and assessing pain, suffering and distress in laboratory animals: A survey of current practice in the UK with recommendations. Lab Anim 36, 378-395. doi:10.1258/002367702320389044

Hawkins, P., Armstrong, R., Boden, T. et al. (2015). Applying refinement to the use of mice and rats in rheumatoid arthritis research. Inflammopharmacology 23, 131-150. doi:10.1007/s1078

Herrmann, K. and Flecknell, P. A. (2018a): Application of humane endpoints and humane killing methods in animal research proposals - a retrospective review. Altern Lab Anim 46, in print.

Herrmann, K. and Flecknell, P. A. (2018b). Severity classification of surgical procedures and application of health monitoring strategies in animal research proposals - A retrospective review. Altern Lab Anim 46, in print.

Home Office (2017). Statistics of scientific procedures on living animals, Great Britain 2016. https://www.gov.uk/government/ statistics/statistics-of-scientific-procedures-on-living-animalsgreat-britain-2016
Hooijmans, C. R., Leenaars, M. and Ritskes-Hoitinga, M. (2010). A gold standard publication checklist to improve the quality of animal studies, to fully integrate the Three Rs, and to make systematic reviews more feasible. Altern Lab Anim 38, 167-182. http://hdl.handle.net/2066/89153

Hurst, J. L. and West, R. S. (2010). Taming anxiety in laboratory mice. Nat Methods 7, 825-826. doi:10.1038/nmeth.1500

Jasiecka, A., Maślanka, T. and Jaroszewski, J. J. (2014). Pharmacological characteristics of metamizole. Pol J Vet Sci 17, 207-214. doi:10.2478/pjvs-2014-0030

Jirkof, P., Cesarovic, N., Rettich, A. et al. (2010). Burrowing behavior as an indicator of post-laparotomy pain in mice. Front Behav Neurosci 4, 165. doi:10.3389/fnbeh.2010.00165

Jirkof, P., Fleischmann, T., Cesarovic, N. et al. (2013). Assessment of postsurgical distress and pain in laboratory mice by nest complexity scoring. Lab Anim 47, 153-161. doi:10.1177/ 0023677213475603

Jirkof, P. (2014). Burrowing and nest building behavior as indicators of well-being in mice. J Neurosci Methods 234, 139-146. doi:10.1016/j.jneumeth.2014.02.001

Jirkof, P., Tourvieille, A., Cinelli, P. and Arras, M. (2015). Buprenorphine for pain relief in mice: Repeated injections vs sustained-release depot formulation. Lab Anim 49, 177-187. doi: $10.1177 / 0023677214562849$

Jirkof, P. (2017). Side effects of pain and analgesia in animal experimentation. Lab Anim 46, 123-128. doi:10.1038/laban.1216

Jirkof, P., Arras, M. and Cesarovic, N. (2018). Tramadol: Paracetamol in drinking water for treatment of post-surgical pain in laboratory mice. Appl Anim Behav Sci 198, 95-100. doi:10.1016/j.applanim.2017.09.021

Jourdan, D., Ardid, D. and Eschalier, A. (2001). Automated behavioural analysis in animal pain studies. Pharmacol Res 43, 103-110. doi:10.1006/phrs.2000.0760

Kalliokoski, O., Jacobsen, K. R., Hau, J. and Abelson, K. S. (2011). Serum concentrations of buprenorphine after oral and parenteral administration in male mice. Vet $J$ 187, 251-254. doi:10.1016/j. tvj1.2009.11.013

Karas, A.Z. (2002). Postoperative analgesia in the laboratory mouse, Mus musculus. Lab Anim (NY) 31, 49-52. doi:10.1038/5000175

Kendall, L. V., Wegenast, D. J., Smith, B. J. et al. (2016). Efficacy of sustained-release buprenorphine in an experimental laparotomy model in female mice. J Am Assoc Lab Anim Sci 55, 66-73. http://www.ingentaconnect.com/content/aalas/jaalas/2016/ 00000055/00000001/art00012

Kilkenny, C., Browne, W. J., Cuthill, I. C. et al. (2010). Improving bioscience research reporting: The ARRIVE guidelines for reporting animal research. PLoS Biol 8, e1000412. doi:10.1371/ journal.pbio.1000412

Kirkden, R. D., Niel, L., Lee, G. et al. (2008). The validity of using an approach-avoidance test to measure the strength of aversion to carbon dioxide in rats. Appl Anim Behav Sci 114, 216-234. doi:10.1016/j.applanim.2008.03.001

Langford, D. J., Bailey, A. L., Chanda, M. L. et al. (2010). Coding of facial expressions of pain in the laboratory mouse. Nat Methods 7 , 447-449. doi:10.1038/nmeth.1455

Leach, M. C., Bowell, V. A., Allan, T. F. and Morton, D. B. (2002a). Aversion to gaseous euthanasia agents in rats and mice. Comp 
Med 52, 249-257. http://www.ingentaconnect.com/contentone/ aalas/cm/2002/00000052/00000003/art00010

Leach, M. C., Bowell, V. A., Allan, T. F. and Morton, D. B. (2002b). Degrees of aversion shown by rats and mice to different concentrations of inhalational anaesthetics. Vet Rec 150, 808-815. doi:10.1136/vr.150.26.808

Leach, M. C., Bowell, V. A., Allan, T. F. and Morton, D. B. (2004). Measurement of aversion to determine humane methods of anaesthesia and euthanasia. Anim Welfare 13, S77-S86.

Leach, M. C., Forrester, A. R. and Flecknell, P. A. (2010). Influence of preferred foodstuffs on the antinociceptive effects of orally administered buprenorphine in laboratory rats. Lab Anim 44, 5458. doi:10.1258/la.2009.009029

Leach, M. C., Klaus, K., Miller and A. L. et al. (2012). The assessment of post-vasectomy pain in mice using behaviour and the Mouse Grimace Scale. PLoS One 7, e35656. doi:10.1371/ journal.pone.0035656

Leidinger, C. S. (2018). Refinement strategies in breeding and keeping of laboratory mice. ( $\mathrm{PhD}$ thesis). Freie Universität Berlin. http://www.diss.fu-berlin.de/diss/servlets/MCRFileNode Servlet/FUDISS_derivate_000000023125/Leidinger_online. pdf?hosts=

Leung, V., Rousseau-Blass, F., Beauchamp, G. and Pang, D. S. (2018). ARRIVE has not ARRIVEd: Support for the ARRIVE (Animal Research: Reporting of in vivo Experiments) guidelines does not improve the reporting quality of papers in animal welfare, analgesia or anesthesia. PLoS One 13, e0197882. doi:10.1371/journal.pone.0197882

Lewis, R. E., Kunz, A. L. and Bell, R. E. (1966). Error of intraperitoneal injections in rats. Lab Anim Care 16, 505-509.

Lidster, K., Jefferys, J. G., Blümcke, I. et al. (2016). Opportunities for improving animal welfare in rodent models of epilepsy and seizures. J Neurosci Methods 260, 2-25. doi:10.1016/j.jneumeth. 2015.09.007

Liles, J. H. and Flecknell, P. A. (1993). The influence of buprenorphine or bupivacaine on the post-operative effects of laparotomy and bile-duct ligation in rats. Lab Anim 27, 374-380. doi:10.1258/002367793780745552

Lilley, E., Armstrong, R., Clark, N. et al. (2015). Refinement of Animal models of sepsis and septic shock. Shock 43, 304-316. doi:10.1097/SHK.0000000000000318

Lipiski, M., Arras, M., Jirkof, P. and Cesarovic, N. (2017). Premedication with fentanyl-midazolam improves sevoflurane anesthesia for surgical intervention in laboratory mice. Exp Biol Med (Maywood) 242, 1287-1298. doi:10.1177/1535370217707730

Liu, S., Zhen, G., Meloni, B. P. et al. (2009). Rodent stroke model guidelines for preclinical stroke trials. J Exp Stroke Transl Med 2, 2-27. doi:10.6030/1939-067X-2.2.2

Makowska, I. J. and Weary, D. M. (2009). Rat aversion to induction with inhalant anaesthetics. Appl Anim Behav Sci 119, 229-235. doi:10.1016/j.applanim.2009.04.003

Marquardt, N. (2013). Comparison of stress reactions induced by carbon dioxide $\left(\mathrm{CO}_{2}\right)$, isoflurane and sevoflurane during the phase of induction of narcosis in mice- a contribution to the refinement of animal research. (PhD thesis). Freie Universität Berlin. http://www.diss.fu-berlin.de/diss/servlets/MCRFileNodeServlet/FUDISS_derivate_000000014349/Marquardt_online.pdf;
jsessionid=95FF7144C8D7E8149422D5DA13957E28?hosts=

Martini, L., Lorenzini, R. N., Cinotti, S. et al. (2000). Evaluation of pain and stress levels of animals used in experimental research. $J$ Surg Res 88, 114-119. doi:10.1006/jsre.1999.5789

Matsumiya, L. C., Sorge, R. E., Sotocinal, S. G. et al. (2012). Using the mouse grimace scale to reevaluate the efficacy of postoperative analgesics in laboratory mice. J Am Assoc Lab Anim Sci 51, 42-49. http://www.ingentaconnect.com/content/aalas/ jaalas/2012/00000051/00000001/art00007

Meijer, M. K., Spruijt, B. M., Van Zutphen, L. F. M. and Baumans, V. (2006). Effect of restraint and injection methods on heart rate and body temperature in mice. Lab Anim 40, 382-391. doi:10.1258/002367706778476370

Miller, A. L. and Richardson, C. A. (2011). Rodent analgesia. Vet Clin North Am Exot Anim Pract 14, 81-92. doi:10.1016/j. cvex.2010.09.004

Miller, A. L., Flecknell, P. A., Leach, M. C. and Roughan, J. V. (2011). A comparison of a manual and an automated behavioural analysis method for assessing post-operative pain in mice. Appl Anim Behav Sci 131, 138-144. doi:10.1016/j. applanim.2011.02.007

Miller, A. L., Wright-Williams, S. L., Flecknell, P. A. and Roughan, J. V. (2012). A comparison of abdominal and scrotal approach methods of vasectomy and the influence of analgesic treatment in laboratory mice. Lab Anim 46, 304-310. doi:10.1258/ la.2012.012078

Miller, A. L., Kitson, G. L., Skalkoyannis, B. et al. (2016). Using the mouse grimace scale and behaviour to assess pain in CBA mice following vasectomy. Appl Anim Behav Sci 181, 160-165. doi:10.1016/j.applanim.2016.05.020

Muir, W. W. and Hubbell, J. A. (2014). Handbook of Veterinary Anesthesia-E-Book. Missouri, USA: Elsevier Health Sciences.

National Competent Authorities (2014). A working document on the development of a common education and training framework to fulfil the requirements under the Directive. http://ec.europa. eu/environment/chemicals/lab_animals/pdf/Endorsed_E-T.pdf

Niel, L. and Weary, D. M. (2007). Rats avoid exposure to carbon dioxide and argon. Appl Anim Behav Sci 107, 100-109. doi:10.1016/j.applanim.2006.08.002

Niel, L., Stewart, S. A. and Weary, D. M. (2008). Effect of flow rate on aversion to gradual-fill carbon dioxide exposure in rats. Appl Anim Behav Sci 109, 77-84. doi:10.1016/j.applanim.2007.02. 004

Penderis, J. and Franklin, R. J. (2005). Effects of pre-versus post-anaesthetic buprenorphine on propofol-anaesthetized rats. Vet Anaesth Analg 32, 256-260. doi:10.1111/j.1467-2995. 2005.00183.x

Peterson, N. C., Nunamaker, E. A. and Turner, P. V. (2017). To treat or not to treat: The effects of pain on experimental parameters. Comp Med 67, 469-482. http://www.ingentaconnect.com/ content/aalas/cm/2017/00000067/00000006/art00002

Percie du Sert, N., Alfieri, A., Allan, S. M. et al. (2017). The IMPROVE guidelines (ischaemia models: Procedural refinements of in vivo experiments). J Cereb Blood Flow Metabol 37, 34883517. doi:10.1177/0271678X17709185

Pound, P. and Nicol, C. J. (2018). Retrospective harm benefit analysis of pre-clinical animal research for six treatment interventions. 
PLoS One 13, e0193758. doi:10.1371/journal.pone.0193758

Reichlin, T. S., Vogt, L. and Würbel, H. (2016). The researchers' view of scientific rigor - Survey on the conduct and reporting of in vivo research. PLoS One 11, e0165999. doi:10.1371/journal. pone.0165999

Rhodes, S. A. (2009). Evaluation of hypothermia in neonatal rats, implications for animal welfare and experimental data. $(\mathrm{PhD}$ thesis). University of Newcastle upon Tyne.

Richardson, C. A. and Flecknell, P. A. (2005). Anaesthesia and post-operative analgesia following experimental surgery in laboratory rodents: Are we making progress? Altern Lab Anim 33, 119-127. https://bit.ly/2PuKgXD

Roughan, J. V., Bertrand, H. G. and Isles, H. M. (2016). Meloxicam prevents COX-2-mediated post-surgical inflammation but not pain following laparotomy in mice. Eur J Pain 20, 231-240. doi:10.1002/ejp.712

Russell, W. M. S. and Burch, R. L. (1959). The Principles of Humane Experimental Technique. London, UK: Methuen. http:// altweb.jhsph.edu/pubs/books/humane_exp/het-toc

Sauer, M., Fleischmann, T., Lipiski, M. et al. (2016). Buprenorphine via drinking water and combined oral-injection protocols for pain relief in mice. Appl Anim Behav Sci 185, 103-112. doi:10.1016/j.applanim.2016.09.009

Schuppli, C., Walterhouse, A., Chew, V. et al. (2017). A better life for research animals by fostering a culture of compassion amongst researchers. ALTEX Proc 6, 13. http://www.altex.ch/ resources/WC10_entire_issue1.pdf

Seymour, T. L., Adams, S. C., Felt, S. A. et al. (2016). Postoperative analgesia due to sustained-release buprenorphine, sustained-release meloxicam, and carprofen gel in a model of incisional pain in rats (Rattus norvegicus). J Am Assoc Lab Anim Sci 55, 300-305. http://www.ingentaconnect.com/content/aalas/ jaalas/2016/00000055/00000003/art00008

Smiler, K. L., Stein, S., Hrapkiewicz, K. L. and Hiben, J. R. (1990). Tissue response to intramuscular and intraperitoneal injections of ketamine and xylazine in rats. Lab Anim Sci 40, 60-64.

Smith, A. J., Clutton, R. E., Lilley, E. et al. (2017). PREPARE: Guidelines for planning animal research and testing. Lab Anim 52, 135-141. doi:10.1177/0023677217724823

Sotocinal, S. G., Sorge, R. E., Zaloum, A. et al. (2011). The rat grimace scale: A partially automated method for quantifying pain in the laboratory rat via facial expressions. Mol Pain 7, 55. doi:10.1186/1744-8069-7-55

Stokes, E., Flecknell, P. and Richardson, C. (2009). Reported analgesic and anaesthetic administration to rodents undergoing experimental surgical procedures. Lab Anim 43, 149-154. doi:10.1258/la.2008.008020

Taylor, K. (2010). Reporting the implementation of the Three Rs in European primate and mouse research papers: Are we making progress? Altern Lab Anim 38, 495-517. https://crueltyfree international.org/sites/default/files/Taylor_3Rs\%20reporting ATLA_2010.pdf
Uhlig, C., Krause, H., Koch, T. et al. (2015). Anesthesia and monitoring in small laboratory mammals used in anesthesiology, respiratory and critical care research: A systematic review on the current reporting in top-10 impact factor ranked journals. PLoS One 10, e0134205. doi:10.1371/journal.pone.0134205

Wells, S. (2017). Pain assessment and new innovations. ALTEX Proc 6, 222. http://www.altex.ch/resources/WC10_entire_issue1. pdf

Wolfensohn, S., Hawkins, P., Lilley, E. et al. (2013a). Reducing suffering in experimental autoimmune encephalomyelitis (EAE). J Pharmacol Toxicol Methods 67, 169-176. doi:10.1016/j.vascn. 2013.01.009

Wolfensohn, S., Hawkins, P., Lilley, E. et al. (2013b). Reducing suffering in animal models and procedures involving seizures, convulsions and epilepsy. J Pharmacol Toxicol Methods 67, 9-15. doi:10.1016/j.vascn.2012.09.001

Wong, D., Makowska, I. J. and Weary, D. M. (2013). Rat aversion to isoflurane versus carbon dioxide. Biol Lett 9, 20121000. doi:10.1098/rsbl.2012.1000

Wright-Williams, S. L., Courade, J. P., Richardson, C. A. et al. (2007). Effects of vasectomy surgery and meloxicam treatment on faecal corticosterone levels and behaviour in two strains of laboratory mouse. Pain 130, 108-118. doi:10.1016/j. pain.2006.11.003

Wright-Williams, S., Flecknell, P. A. and Roughan, J. V. (2013). Comparative effects of vasectomy surgery and buprenorphine treatment on faecal corticosterone concentrations and behaviour assessed by manual and automated analysis methods in C57 and $\mathrm{C} 3 \mathrm{H}$ mice. PLoS One 8, e75948. doi:10.1371/journal. pone. 0075948

Young, A. (2006). Halothane induction results in differing behaviours compared with carbon dioxide mixed with oxygen when used as a rat euthanasia agent. Anim Technol Welfare 5, 49-59.

Ziemann, A. E., Allen, J. E., Dahdaleh, N. S. et al. (2009). The amygdala is a chemosensor that detects carbon dioxide and acidosis to elicit fear behavior. Cell 139, 1012-1021. doi:10.1016/j. cell.2009.10.029

\section{Conflict of interest}

The authors declare that they have no conflicts of interest.

\section{Acknowledgements}

We acknowledge the support of the German Research Foundation and the Open Access Publication Fund of the Freie Universität Berlin. We are very grateful to Thorsten Busse for his help in developing an electronic database for comparing the data. And we are very thankful to the German foundation SET, who financially supported this project. We also thank ZEBET (FK 1329-472) whose travel grant enabled the first author to present the project results at international conferences. 